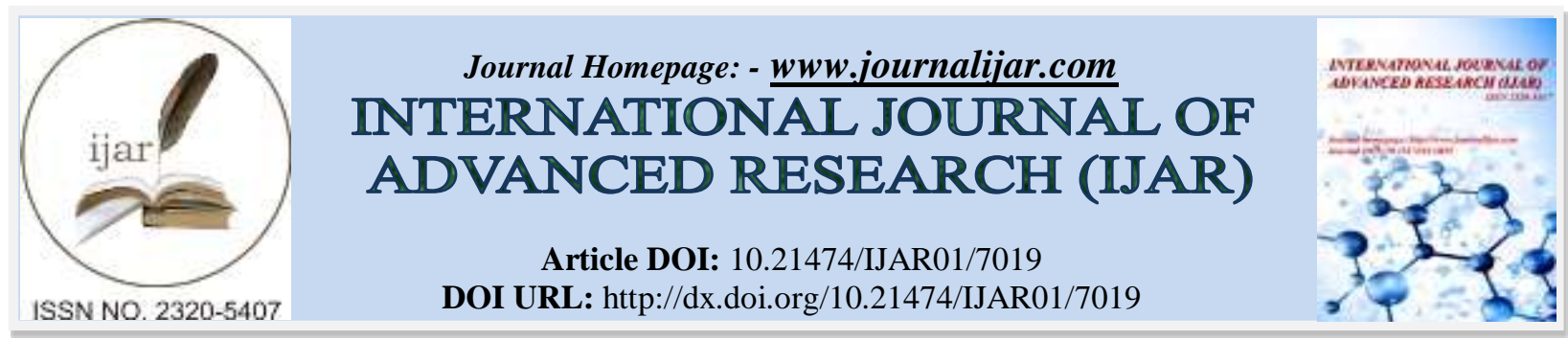

RESEARCH ARTICLE

\title{
THE EFFECT OF PREGABALIN VERSUS CARBAMAZEPINE ON THE GINGIVA OF ALBINO RATS WITH THE POSSIBLE MODULATORY ACTION OF ACASIA ARABICA.
}

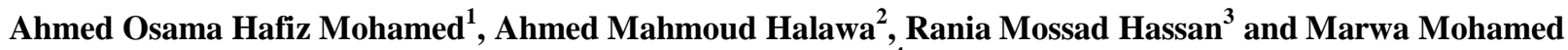 \\ Abd El-Hameed ${ }^{4}$. \\ 1. B.D.S. 6 October University (2004) MSC. Oral Biology, Cairo University (2012), Assistant Lecturer of Oral \\ Biology, Faculty of Dentistry, MSA University. \\ 2. Professor and Head of Oral Biology department, Faculty of Dentistry, Ain Shams University. \\ 3. Professor of Oral Biology, Faculty of Dentistry, Badr University in Cairo. \\ 4. Lecturer of Oral Biology, Faculty of Dentistry, Ain Shams University.
}

\section{Manuscript Info}

Manuscript History

Received: 02 March 2018

Final Accepted: 04 April 2018

Published: May 2018

Keywords:-

Epilepsy, Pregabalin, Carbamazepine,

Acacia Arabica, Gingiva, Immuno

histochemically.
Abstract

Aim: The aim of this study was to compare the effect of anticonvulsant Pregabalin versus Carbamazepine, with and without Acacia Arabica on the rats' gingiva.

Materials and methods: 35 adult male albino rats were divided into: control group contained seven rats received distilled water for three weeks, experimental group I contained seven rats received Carbamazepine $(20 \mathrm{mg} / \mathrm{kg})$, subgroup I contained seven rats which received Carbamazepine $(20 \mathrm{mg} / \mathrm{kg}$ ) and Acasia Arabica $(100 \mathrm{mg} / \mathrm{kg})$, group II contained seven rats received Pregabaline $(20 \mathrm{mg} / \mathrm{kg})$ and subgroup II contained seven rats received Pregabaline $(20 \mathrm{mg} / \mathrm{kg})$ and Acasia Arabica $(100 \mathrm{mg} / \mathrm{kg})$. After three weeks, all rats were terminated and the mandibular molar regions were excised, fixed then decalcified and stained with $\mathrm{H} \&$ E. The epithelium thickness was measured using morphometric analysis and the gingival specimens were examined for the expression of $\mathrm{Ki}-67$ antigen.

Results: The side effects on the gingiva either histologically or immuno histochemically were severe with Carbamazepine and mild with Pregabalin. Results also showed a great modulating effect of Acacia Arabica on the enlarged gingiva.

Conclusion: Pregabalin treatment has milder deletarious effects on the gingiva when compared with Carbamazepine.

Copy Right, IJAR, 2018,. All rights reserved.

\section{Introduction:-}

Epilepsy is a common chronic neurological disorder in humans. It is a condition in which the patient has recurrent seizures. The prevalence of epilepsy in developed countries reaches approximately $1 \%$, rising to $2 \%$ in less developed countries (Correa et al., 2011).

The possible treatment options for patients suffering from epilepsy are antiepileptic drugs (AEDs). All AEDs have relatively high incidence of adverse effects a major cause of discontinuing the treatment. With respect to carbamazepine, the most common side effects are: dizziness, allergic skin reactions, dry mouth and gingival 
enlargement (Subaniec et al., 2005). Thus new antiepileptic drugs have been developed in the last decade to overcome some of these outcomes. (Walia et al., 2004).

The exact mechanism of anticonvulsant induced gingival overgrowth is not completely understood. All forms of gingival overgrowth have a common histological alteration as acanthosis of the epithelium, elongated rete pegs and a massive increase of connective tissue extracellular matrix (Aragon and Burneo, 2007).

Babul, whose botanical name (acacia Arabica), mainly planted in India and Africa, it yields a gum known as babul gum. Babul contains tannin and gallic acid, which have antibacterial, antimicrobial, antiviral, anti-inflammatory effects (Tangade et al., 2012).

An analysis of plaque index, gingival index and bleeding on probing index using acacia arabica containing toothpaste were carried out by Tangade et al. and reductions in all indeces in the acacia arabica containing toothpaste were noticed compared with regular toothpaste.

Currently, new cell proliferation markers are being used to evaluate cell proliferation. However, PCNA and Ki-67 are considered the classic markers of cell proliferation and are in routine use by pathologists (Oka et al., 2011).

\section{Materials and method:-}

Animals:

Thirty five adult male albino rats with average body weight 150-200 gram were housed in separate cages (3-4 rats each) in the Animal House of Ain Shams University for three weeks. Rats were kept under good ventilation and adequate stable diet.

All the experimental procedures were approved by the Research Ethics committee of the Faculty of Dentistry, Ain Shams University.

Experimental design:-

The rats were divided into:

- Control group: contains seven rats which received distilled water daily for three weeks via oral gastric tube.

- Experimental groups:

Group I: contains seven rats which received daily oral dose of Carbamazepine $(20 \mathrm{mg} / \mathrm{kg})$ for three weeks via oral gastric tube.

Subgroup I: contains seven rats which received daily oral dose of Carbamazepine ( $20 \mathrm{mg} / \mathrm{kg})$ followed immediately by Acasia Arabica (100 mg/kg) for three weeks via oral gastric tube.

Group II: contains seven rats which received daily oral dose of Pregabaline $(20 \mathrm{mg} / \mathrm{kg})$ for three weeks via oral gastric tube.

Subgroup II: contains seven rats which received daily oral dose of Pregabaline (20 mg/ $\mathrm{kg})$ followed immediately by Acasia Arabica $(100 \mathrm{mg} / \mathrm{kg}$ ) for three weeks via oral gastric tube.

After three weeks from the beginning of the experiment, all rats were terminated by intra peritoneal injection of overdose of anesthesia, the mandibular molar regions of the right side were excised and processed for the subsequent examination by the following methods:

1) Histological examination:

The specimens were fixed immediately in $10 \%$ phosphate- buffered formalin solution for 48 hours, then transferred to $12.5 \%$ Ethylene diamine tetra acetic acid solution (EDTA) for four weeks till complete decalcification. The specimens were then dehydrated and embedded in paraffin wax blocks. The embedded specimens were sectioned bucco-lingually in the first molar area, then sectioned by microtome ( 5 microns thick). The specimens were stained by Hematoxyline and Eosin (H\&E) stain and were examined by light microscope.

\section{2) Immuno-histochemical examination:}

The gingival specimens from the mandibular molar region were processed to be examined for the expression of Ki67 antigen.

Immuno-histochemical staining technique:

A monoclonal antibody to Ki-67, the mouse MAb anti-rat Ki-67 (clone MIB-5; DAKO). 
Tissue sections were deparaffinized by passing through xylene and alcohol, immersed in double distilled water then heated in a conventional microwave oven $(650 \mathrm{~W})$ for three-five minutes cycles in $0.001 \mathrm{M}$ disodium EDTA $(\mathrm{pH}$ 8.0). The slides were permitted to cool down to room temperature before washing in PBS (pH 7.4).

The slides were blocked and incubated with Ki-67 antibody (1/200) overnight at $+4 \mathrm{C}$, washed in PBS, and sequentially incubated with biotin-labeled goat anti-rabbit or horse anti-mouse IgG for 30 minutes, then the slides were incubated with a preformed biotin avidin complex for 30 minutes.

The slides were incubated with $3 \% \mathrm{H}_{2} \mathrm{O}_{2}$ in methanol at $+4 \mathrm{C}$ for 15 minutes. The sections were treated with a diaminobenzidine (DAB) substrate kit (Vectastain Elite ABC-POD) for 2 to 7 minutes under microscopic observation and washed in DDW.

Sections were then rinsed gently with distilled water, counter stained with hematoxylin. Slides were examined under the light microscope at magnification (x 200) and the number of Ki-67 positive cells divided by the total cell number in the basal and suprabasal cell layers was estimated and treated statistically (Saito et al., 1999).

\section{3) Morphometric analysis:-}

A midline to the rete pegs was drawn extending from the base of each rete peg to the beginning of the keratin layer then a continuing new line was drawn passing through the full thickness of keratin layer. Five readings were taken for each image and then the average thickness was calculated by Leica QWin Plus software program (Mukherjee et al.,2010).

\section{Results:-}

\section{Histological results}

\section{Control group:}

The gingiva of the control animals showed that epithelium is formed of four categories of cells. The lamina propria was formed of two layers. Moreover, few chronic inflammatory cells were encountered, in addition to apparently normal blood vessels lining (Fig. 1).

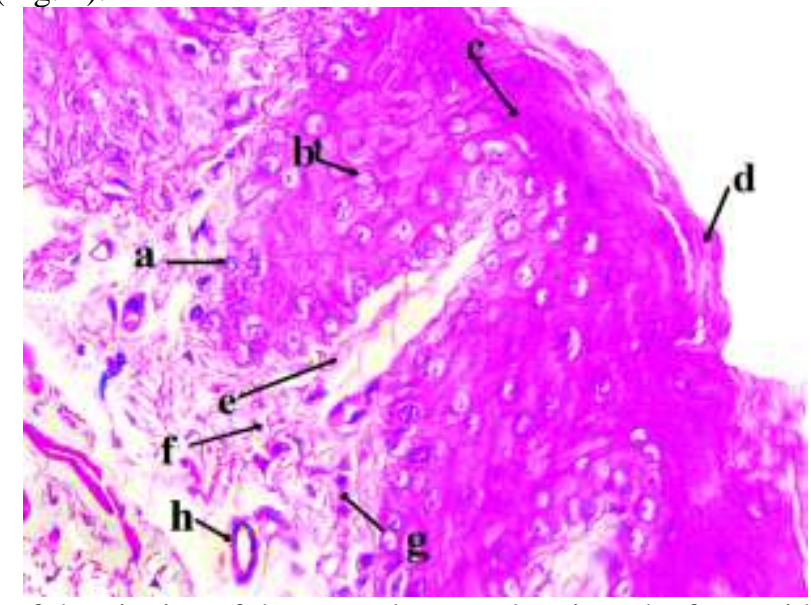

Fig(1):- A photomicrograph of the gingiva of the control group showing: the four epithelial layers, basal (a), prickle (b), granular (c), keratinous (d), papillary (e), reticular (f) layers, few chronic inflammatory cells (g) and normal bvs

(h). (H\&E X 400)

\section{Experimental groups:- \\ Group I:}

Histological examination of the gingiva of the rats showed apparent hyperkeratosis, acanthosis, , nuclear division , cytokinesis and clubbing of the rete pegs, basement membrane discontinuity was observed. The lamina propria showed an obvious increase in the number of inflammatory cells and engorged blood vessels (Fig. 2). 


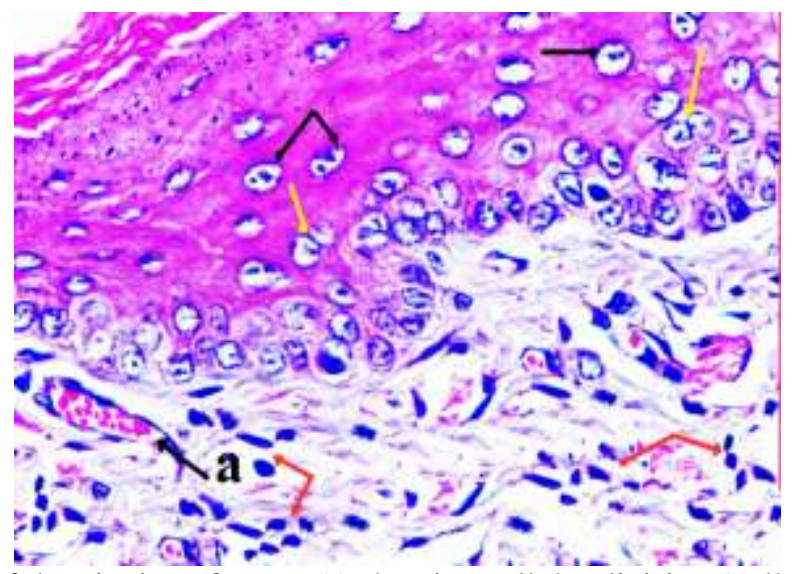

Fig(2):- A photomicrograph of the gingiva of group (I) showing cellular division (yellow arrows), cytokinesis (black arrows), an increase in the inflammatory cells (a) and engorged blood vessels (b). (H\&E X 400)

\section{Subgroup I:}

Histologically the gingiva showed a slight hyperkeratosis, slight elongation of rete pegs, very little signs of nuclear division and cytokinesis with normal basement membrane. The lamina propria showed a slight increase in the number of inflammatory cells (Fig. 3).

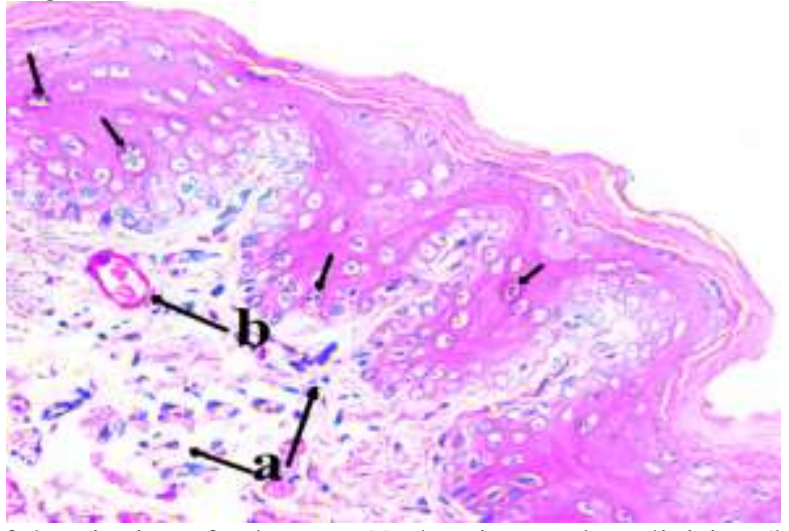

Fig(3):- A photomicrograph of the gingiva of subgroup (I) showing nuclear division (black arrows), a slight increase in the number of inflammatory cells (a) and normal blood vessels (b). (H\&E X 400)

\section{Group II:}

Histologically the gingiva showed nearly normal histological features of the surface epithelium, a slight elongation of the epithelial ridges, intact basement membrane and very few signs of nuclear division and cytokinesis. The lamina propria showed a slight increase in the inflammatory cells (Fig. 4).

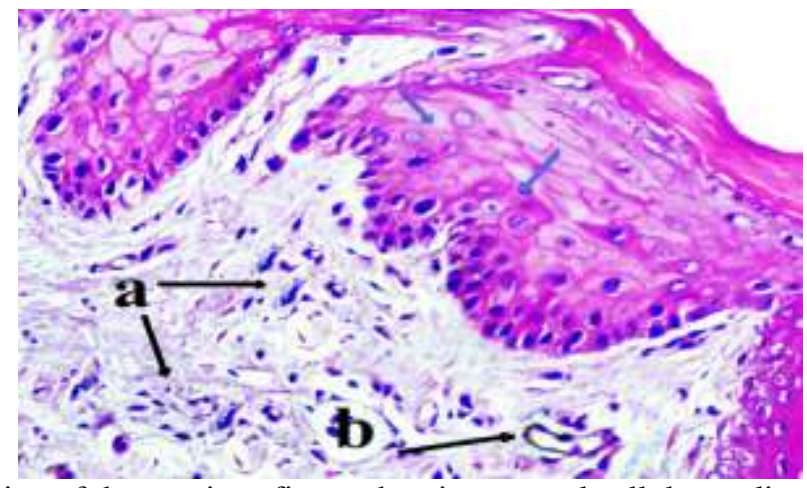

Fig(4):- A higher magnification of the previous figure showing normal cellular outline (blue arrows), slight increase of inflammatory cells (a) and normal blood vessels (b). (H\&E X 400) 


\section{Subgroup II:}

Histologically the gingiva showed the keratinous layer and the epithelial ridges with almost normal thickness, no obvious signs of nuclear division or cytokinesis were detected in the epithelial cells. The lamina propria showed a decrease in the number of the chronic inflammatory cells (Fig. 5).

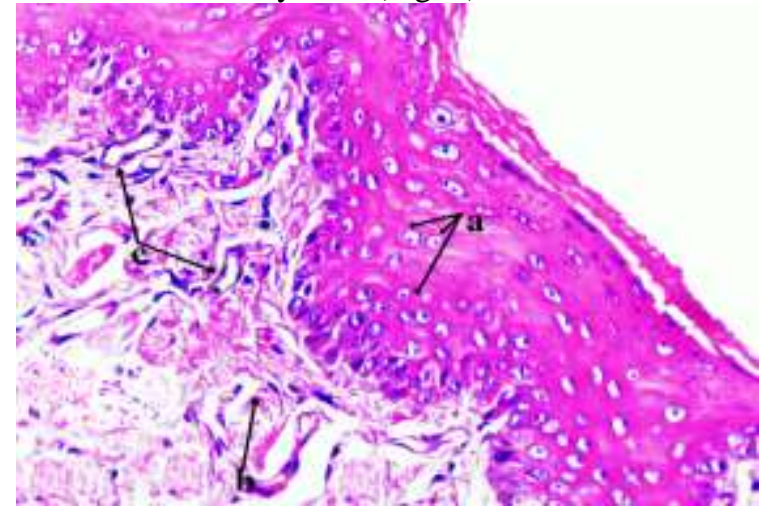

Fig(5):- A photomicrograph of the gingiva of subgroup (II) showing normal cellular outline (a), few inflammatory cells (b) and normal lining of the blood vessels (c). (H\&E X 400)

\section{Immunohistochemical results:- \\ Control group \\ Group I:}

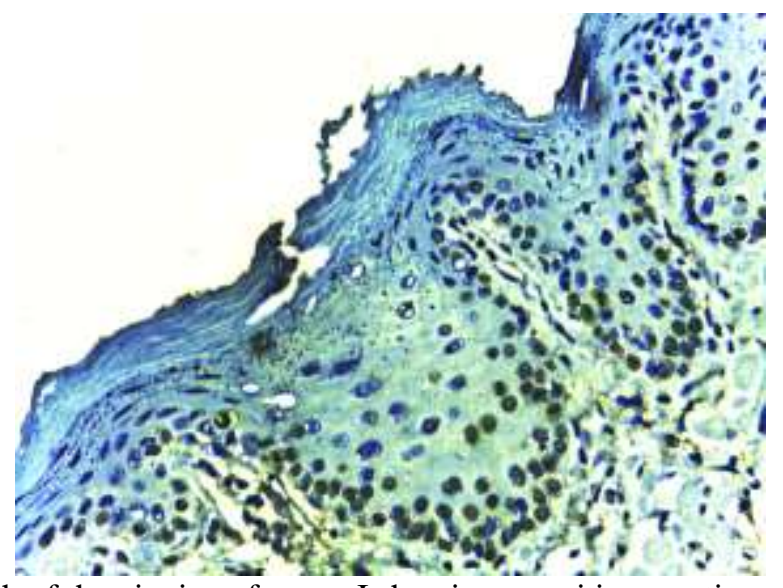

Fig.(6):- A photomicrograph of the gingiva of group I showing a positive reaction of the all basal cells, most of parabasal cells and sparse cells in the prickle cell layer. (Ki-67 antibody X400)

\section{Subgroup I:}

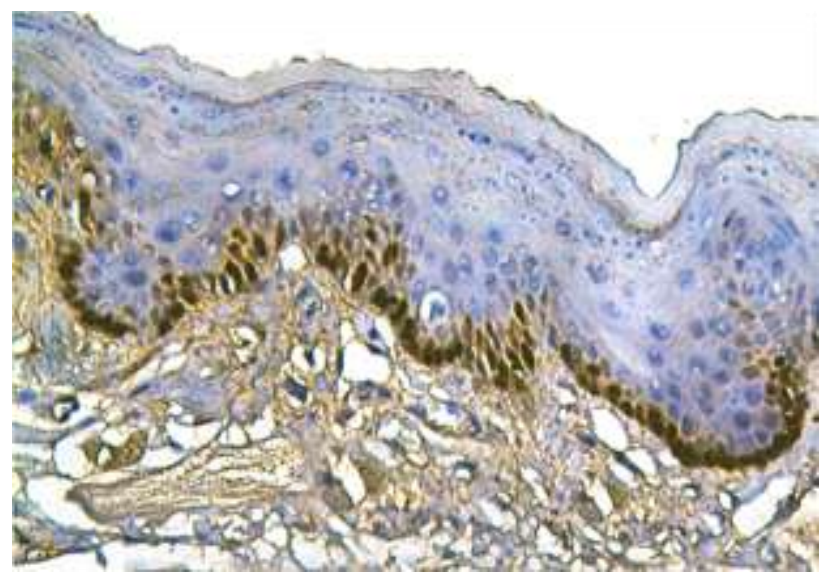


Fig.(7):- A photomicrograph of the gingiva of subgroup I showing a positive reaction of the most of basal cells and Group II: a little number of parabasal cells. (Ki-67 antibody X400)

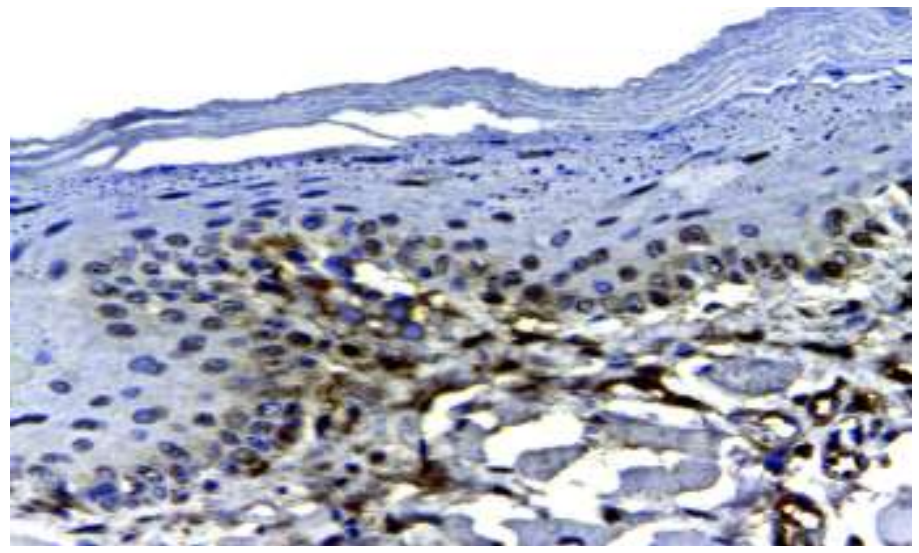

Fig.(8):- A photomicrograph of the gingiva of group (II) showing a positive reaction of some of basal and few parabasal cells. (Ki-67 antibody X400)

\section{Subgroup II}

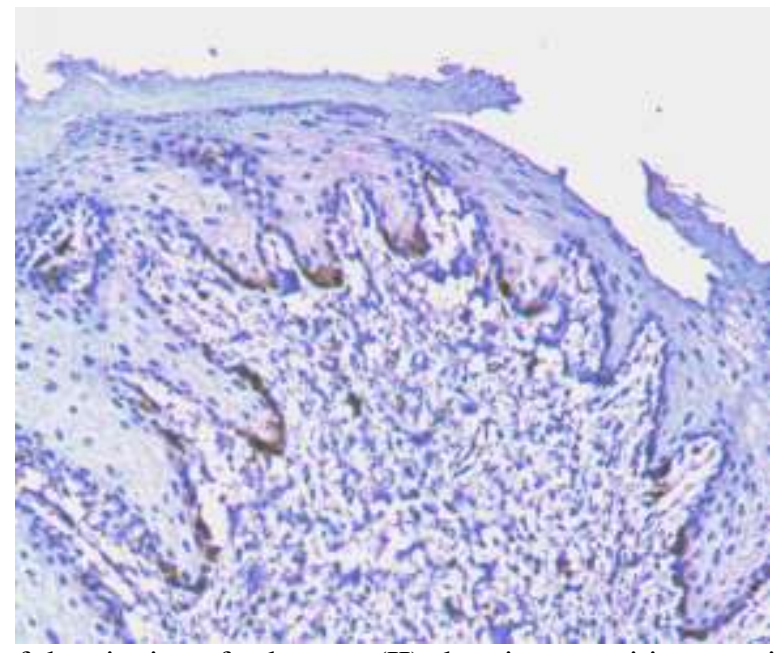

Fig.(9):- A photomicrograph of the gingiva of subgroup (II) showing a positive reaction of few basal cells to Ki-67.

(Ki-67 antibody X400)

\section{Statistical Analysis:-}

Statistical Analysis regarding the epithelial rete pegs length showed a statistically significant difference between control group and group I , subgroup I and group II ( $\mathrm{p}<0.05$ ), and a statistically non-significant difference between control group and subgroup II ( $>>0.05)$.

Statistical Analysis regarding the thickness of keratin layer showed a statistically significant difference between control group and (group I and subgroup I) ( $<<0.05$ ), a statistically non significant difference between control group and (group II and subgroup II) ( $\mathrm{p}>0.05)$.

Statistical Analysis regarding the number of cells expressing Ki67 to total number of cells showed a statistically significant increase in the mean values of both group I and subgroup I in comparison to the control group ( $<<0.05$ ), and a statistically non- significant decrease in the values of both group II subgroup II in comparison to the control group ( $p>0.05)$. 


\section{Discussion:-}

In our study, histological examination of the gingival tissue of the rats of group I showed increased mitotic figures and apparent hyperkeratosis. These came in accordance with Vittek et al., 1983, who found that the rats injected daily with phenytoin for 6 days i.p. (30 mg/100 g) showed hyperkeratosis of the epithelium and increased mitotic figures. They attributed that to the significant increase in mitotic frequency and short mitotic duration.

In the current study, histological examination of the gingiva group I showed some signs of nuclear division within the cells and cytokinesis in some cells. This is similar to Nascimento et al., 1985, who found that tegretol treatment induced a marked increase in the mitotic figures in the basal layer. They also observed irregular junctional epithelium containing multinucleated cells and a marked increase in the proliferative activity of the basal layer. They explained that by the proliferative effect of tegretol on the basal epithelial layer and gingival fibroblasts.

In the present study, H\&E sections of the gingiva of rats from group I showed blood vessels engorged with red blood corpuscles. This finding is similar to that described by El-Gaafarawi \& Abouel-Magd, 2015, who mentioned that tegretol at a daily dose of $3.6 \mathrm{mg} / 100 \mathrm{~g}$ body weight on the liver of the pregnant rats showed intercellular hemorrhage and congested blood vessels.

Immunohistochemical examination of the gingiva of group I revealed a positive nuclear ki-67 immuno-expression in the basal, suprabasal and prickle cells. These findings were in agreement with several studies as Saito et al., 1999, who examined the expression of $\mathrm{Ki}-67$ antigen in 11 hyperplastic gingival tissues induced by nifidepine and phenytoin and found that epithelial cells expressing ki-76 antigen in the hyperplastic gingival tissues was more than $10 \%$ higher than that in the controls.

In this study, histological examination of the gingiva of the rats of subgroup I showed a modulatory action regarding to hyperkeratosis and the length of the rete pegs. This finding is similar to that described by Mohan et al., 2017, who found that acacia nilotica induced a great improvement regarding the epithelial hyperplasia and hyperkeratosis returning the epithelial architecture as seen in control group.

Also, in this study acacia arabica administration was accompanied by a decrease in the mitotic figures and a decrease in the cells showing positive reaction for ki-67 expression. These findings were similar to that recorded by Meena et al., 2006, reported that the chemopreventive activity of acacia nilotica gum, flower and leaf aqueous extracts inhibits tumor cell proliferation, decreased the mitotic activity\& selectively toxic to tumor cells.

Immunohistochemical examination of the surface epithelium of the gingiva of group II revealed a slight decrease in the number of positively stained cells to Ki-67. This finding is in agreement with those of Demirtzoglou et al., 2013, who investigated the in vitro effect of pregabalin on human genetic material, and found that pregabalin at therapeutic doses $5 \mu \mathrm{g} / \mathrm{ml}, 10 \mu \mathrm{g} / \mathrm{ml} 15 \mu \mathrm{g} / \mathrm{ml}$ and $30 \mu \mathrm{g} / \mathrm{ml}$ induced statistically non-significant decrease in Proliferation Rate Index and Mitotic Index values.

\section{Conclusion:-}

This study concluded that pregabaline had a little side effect on the gingiva when compared to carbamazepine. Acacia Arabica induced a favorable modulating effect on the overgrown gingiva. 


\section{References:-}

1. Aragon, C. E., \& Burneo, J. G. (2007): Understanding the patient with epilepsy and seizures in the dental practice. Journal of the Canadian Dental Association., 73(1): 71-76.

2. Corrêa, J. D., Queiroz-Junior, C. M., Costa, J. E., Teixeira, A. L., \& Silva, T. A. (2011): Phenytoin-induced gingival overgrowth. A review of the molecular, immune, and inflammatory features. ISRN dentistry., 10-5402.

3. Dermitzoglou, G., Chrysoglou, S. I., Papazisis, G., \& Iakovidou-Kritsi, Z. (2013): Pregabalin's effect on human genetic material: in vitro study. Aristotle University Medical Journal., 40(2): 33-39.

4. El-Gaafarawi, I., \& Abouel-Magd, M. (2015): Teratogenic effect of Carbamazepine Administration in Pregnant Rats. Egyptian Journal of Hospital Medicine., 59: 244- 257.

5. Kulbir S. Walia, Elizabeth A. Khan, Dong H. Ko, et al. (2004): Side Effects of Antiepileptics. World Institute of Pain, Pain Practice, Volume 4, Issue 3., 194-203.

6. Meena, P. D., Kaushik, P., Shukla, S., Soni, A. K., Kumar, M., \& Kumar, A. (2006): Anticancer and antimutagenic properties of Acacia nilotica (Linn.) on 7, 12-dimethylbenz (a) anthracene-induced skin papillomagenesis in Swiss albino mice. Asian Pac J Cancer Prev., 7(4): 627-632.

7. Mohan, S., Thiagarajan, K., \& Chandrasekaran, R. (2017): Evaluation of ethyl gallate for its antioxidant and anticancer properties against chemical-induced tongue carcinogenesis in mice. Biochemical Journal., 474(17): 3011-3025.

8. Mukherjee, S., Ray, J. G., \& Chaudhuri, K. (2010): Microscopic analysis of histological and immunohistochemical sections to differentiate normal, precancer and cancerous oral squamous epithelial tissues. Microscopy: Science Technology, Applications and Education., (3): 993-1000.

9. Nascimento, A., Castro Barreto, R., Bozzo, L., \& Almeida, O. P. (1985): Interaction of phenytoin and inflammation induces gingival overgrowth in rats. Journal of periodontal research., 20(4): 386-391.

10. Oka, S., Uramoto, H., Shimokawa, H., Iwanami, T., \& Tanaka, F. (2011): The expression of Ki-67, but not proliferating cell nuclear antigen, predicts poor disease free survival in patients with adenocarcinoma of the lung. Anticancer research., 31(12): 4277-4282.

11. Saito, K., Mori, S., Tanda, N., \& Sakamoto, S. (1999): Expression of p53 protein and Ki-67 antigen in gingival hyperplasia induced by nifedipine and phenytoin. Journal of periodontology., 70(6): 581-586.

12. Saito, K., Mori, S., Tanda, N., \& Sakamoto, S. (1999): Expression of p53 protein and Ki-67 antigen in gingival hyperplasia induced by nifedipine and phenytoin. Journal of periodontology., 70(6): 581-586.

13. Sobaniec W, Kulak W, Strzelecka J, Smigielska-Kuzia J, Boćkowski L. (2005): A comparative study of vigabatrin vs. carbamazepine in monotherapy of newly diagnosed partial seizures in children. Pharmacol Rep., 57(5): 646-53.

14. Tangade, P. S., Mathur, A., Tirth, A., \& Kabasi, S. (2012): Antigingivitis Effects of Acacia arabicacontaining Toothpaste. Chinese Journal of Dental Research., 15(1): 49.

15. Vittek, J., Gordon, G. G., Rappaport, S. C., Munnangi, P. R., \& Southren, A. L. (1983): Phenytoin effect on the proliferation of rat oral epithelium is mediated by a hormonal mechanism. Cell differentiation., 12(6): 335-339. 